
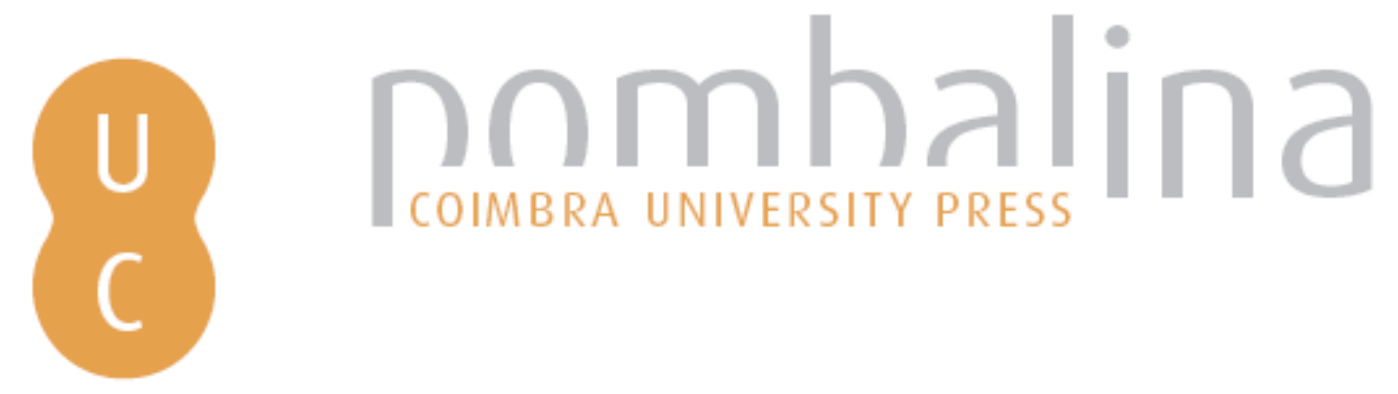

\title{
Turismo e património imaterial: das políticas e suas realidades no caso das festas na região metropolitana de Goiânia
}

\author{
Autor(es): $\quad$ Almeida, Maria Geralda de; D'Abadia, Maria Idelma Vieira; Pinto, \\ Jakelline Graziela; Mota, Rosiane Dias \\ Publicado por: Imprensa da Universidade de Coimbra \\ URL \\ persistente: \\ URI:http://hdl.handle.net/10316.2/30792 \\ DOI: \\ DOI:http://dx.doi.org/10.14195/978-989-26-0244-8_28 \\ Accessed : $\quad$ 26-Apr-2023 11:08:53
}

A navegação consulta e descarregamento dos títulos inseridos nas Bibliotecas Digitais UC Digitalis, UC Pombalina e UC Impactum, pressupõem a aceitação plena e sem reservas dos Termos e Condições de Uso destas Bibliotecas Digitais, disponíveis em https://digitalis.uc.pt/pt-pt/termos.

Conforme exposto nos referidos Termos e Condições de Uso, o descarregamento de títulos de acesso restrito requer uma licença válida de autorização devendo o utilizador aceder ao(s) documento(s) a partir de um endereço de IP da instituição detentora da supramencionada licença.

Ao utilizador é apenas permitido o descarregamento para uso pessoal, pelo que o emprego do(s) título(s) descarregado(s) para outro fim, designadamente comercial, carece de autorização do respetivo autor ou editor da obra.

Na medida em que todas as obras da UC Digitalis se encontram protegidas pelo Código do Direito de Autor e Direitos Conexos e demais legislação aplicável, toda a cópia, parcial ou total, deste documento, nos casos em que é legalmente admitida, deverá conter ou fazer-se acompanhar por este aviso.

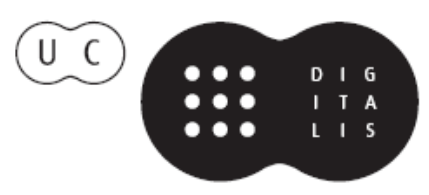




\section{TRUNFOS DE UMA}

\section{EOGRAFIA ACIVA}

\section{DESENVOLVIMENTO LOCAL,}

AMBIENTE,

ORDENAMENTO

E TECNOLOGIA

Norberto Santos

Lúcio Cunha

COORDENAÇÃO 
Maria Geralda de Almeida, Maria Idelma Vieira D'Abadia, Jakelline Graziela Pinto, Rosiane Dias Mota

Universidade Federal de Goiás - UFG

\section{TURISMO E PATRIMÔNIO IMATERIAL. DAS POLÍTICAS E SUAS REALIDADES NO CASO DAS FESTAS NA REGIÃO METROPOLITANADE GOIÃNIA.}

\section{INTRODUÇÃO}

Por meio de uma discussão sobre festas como patrimônio na região metropolitana de Goiânia pretende-se, neste artigo, analisar a valorização das festas e como estas adquirem uma importância para justificar sua apropriação pelas políticas da cultura e do turismo. Também, irá revelar uma faceta da apropriação social da cidade multifuncional, pelo viés do patrimônio imaterial. Esse patrimônio, considerado também como cultural, engloba "o conjunto de bens tangíveis e intangíveis, que sáo herdados do passado ou criados recentemente", na definição da UNESCO, citada por Vallbona e Costa (2003). É possível afirmar que o patrimônio é o conjunto de elementos simbólicos, reproduzido no espaço das cidades e que ajuda a configurar a identidade territorial daqueles que ali se encontram, uma vez legitimados socialmente.

O enfoque será sobre as festas, em duas grandes vertentes: a primeira, com destaque para aquelas que acontecem no meio rural e que estão presentes no urbano, as folias; e a segunda, as festas de padroeiros, que se reproduzem em cidades das mais diversas escalas. Elas constituem elementos importantes que distinguem seus participantes, organizadores e seguidores entre outros grupos sociais, dando-lhes uma identidade cultural. Também, as festas nos animam a refletir sobre as possibilidades delas se tornarem produtos turísticos e fortalecidas enquanto patrimônio de uma comunidade.

Em ambas as festividades, seremos guiados pela hipótese de que o patrimônio desempenha um importante papel da representação simbólica da identidade. Por ele, há o entendimento de que patrimônio é um enlace com o passado que provê de "marcos de referência para que possamos reconhecer o entorno e a nós mesmos", nas palavras de Baillart citado por Vallbona e Costa (2003). A valorizaçáo atual do patrimônio, seu uso e desfrute estáo muito vinculados às práticas do turismo. Nesse sentido, a turistificação das festas evidencia o interesse dos agentes do turismo pela identidade e pelo patrimônio cultural da sociedade.

Embora o enfoque seja para o patrimônio na região metropolitana de Goiânia, o tema poderá ter interesse para outras regióes metropolitanas que têm a mesma preocupação. Essa discussão pode colaborar com as políticas de lazer, tendo como cerne o turismo, as formas de repensar a apropriação do espaço e a gestão dos bens culturais, sobretudo, aquelas que refletem na dimensão territorial. 
Para a realização da pesquisa, foi feito trabalho de campo, consulta a fontes existentes nas dioceses, sites e entrevistas semi-estruturadas com os participantes e organizadores e reportagens jornalísticas e consulta à bibliografia disponível. Para as informaçóes referentes ao turismo e à cultura, recorreu-se aos sites das secretarias municipais e estaduais. Convém ressaltar que há escassez das fontes o que toma este estudo preliminar ainda mais relevante.

A primeira seção deste artigo abrirá a discussão sobre a cidade e a metrópole.

Nela, as manifestaçóes culturais imateriais serão apresentadas como produto turístico. A seção posterior relatará as experiências de festas religiosas na região metropolitana no caso de Goiânia. A terceira seçáo falará das folias como uma tradição sertaneja presente na metrópole. Por fim, na quarta seção, as políticas para a cultura e o turismo na região metropolitana goiana serão discutidas. As cidades refletem um modo de vida próprio, convém repetir, se se considerar o fato de que os sujeitos, ao se inserirem nela, produzem uma dimensão cultura1 própria.

\section{Das leituras de Ruralidades e Lazer na Cidade Metrópole}

A população, principalmente a brasileira, deslocou-se para a cidade nas últimas três décadas do século xx. Isso proporcionou um crescimento rápido e significativo das cidades, das metrópoles no Brasil. Na contemporaneidade, as metrópoles são lugares ideais para as sucessivas adaptaçóes do homem ao moderno (Santos, 2001). Com a globalização, este autor afirma que os tipos culturais são diversificados e. também, aumenta-se a variedade de situaçóes territoriais e as mutaçóes, o que conduz a um permanente refazer na forma, na função, no dinamismo e sentido da metrópole.

Goiânia ainda não é uma metrópole, mas já constituiu uma região metropolitana criada pela Lei Complementar Estadual n ${ }^{\circ} 27$, de 30 de dezembro de 1999, art. l’ $^{\circ}$ com nova redação dada pela Lei Complementar nO 54, de 23 de maio de 2005. A Região Metropolitana de Goiânia (RMG) engloba treze municípios: Goiânia, Trindade, Goianira, Santo Antônio de Goiás, Nerópolis, Goianápolis. Senador Canedo, Aparecida de Goiânia, Hidrolândia, Aragoiânia, Bela Vista, Guapó e Abadia de Goiás (Figura 1).

Conforme dados do Instituto Brasileiro de Geografia e Estatística - IBGE (2009), a RMG tem importante papel sociocultural e econômico por produzir cerca de $60 \%$ do PIB do Estado de Goiás, abarcar 1/3 dos eleitores e aproximadamente $80 \%$ dos estudantes universitários do estado. A Regiáo reúne, ainda, cerca de $35 \%$ da população estadual, o que faz de Goiânia o 13 o Município mais populoso do país, além de ser um grande centro de compras, feiras de confecçôes. Tais aspectos caracterizam a atuação de Goiânia no espaço brasileiro como uma metrópole regional.

Os treze municípios da RMG ocupam uma área de $5.787 \mathrm{~km} 2$, com uma população total de mais de dois milhóes de pessoas (conforme dados da Câmara Municipal de Goiânia). A Capital goiana é a mais populosa cidade do estado, visto que possui um contingente populacional, estimado para 2009, de 1.281.975 habitantes, seguido de Aparecida de Goiânia com estimativa de 510.770 moradores para o corrente ano. Com menor contingente, destaca-se o município de Santo Antônio de Goiás com urna população estimada de 4.230 habitantes. 
Figura 1 - Regiáo Metropolitana de Goiânia.
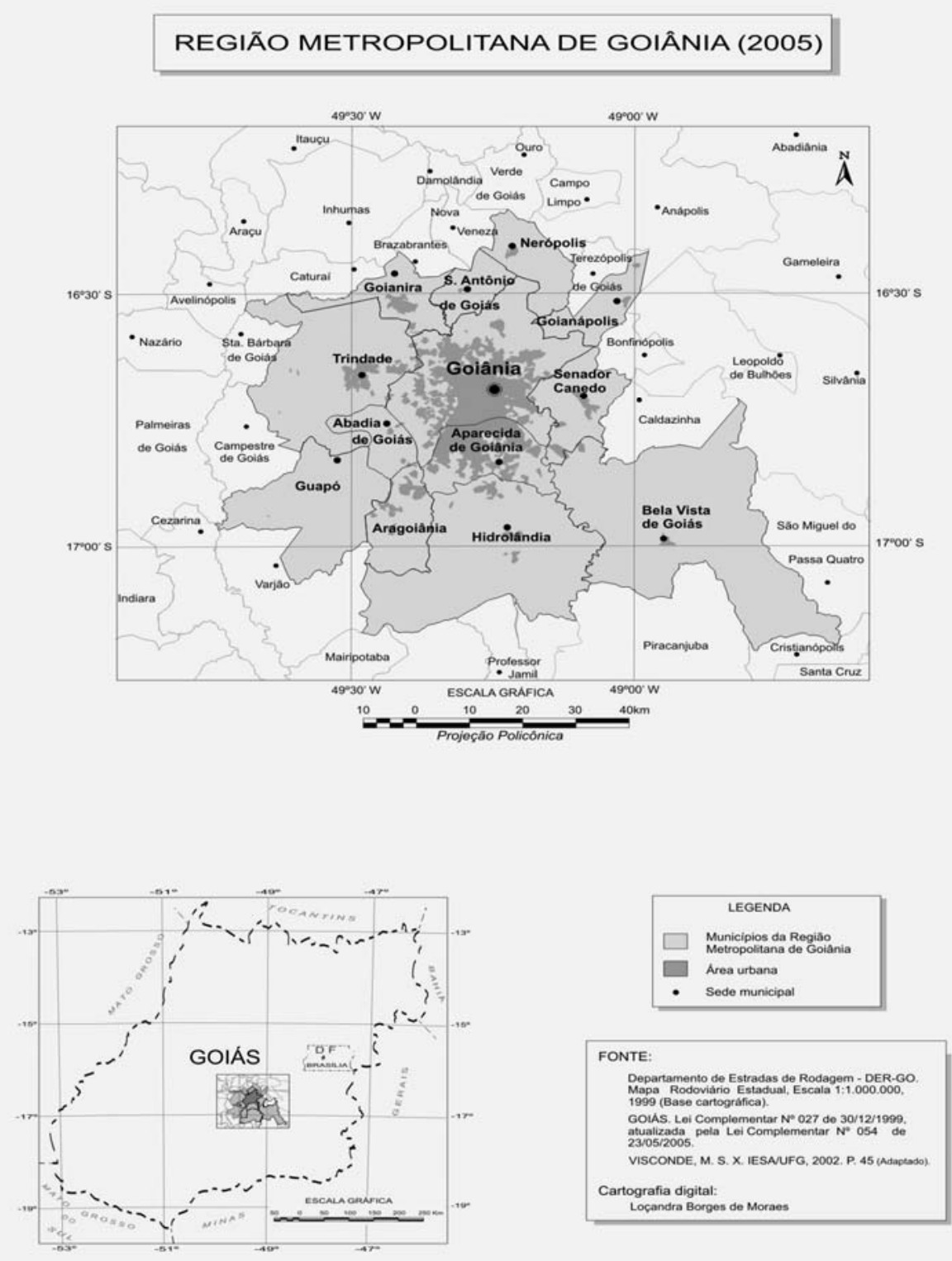

A vida na metrópole, de certa forma, é condicionada pela relação de habitantes com a dinâmica urbana. A cidade se desenvolve. Ao fazê-lo se apropria do espaço por meio de forças produtivas e estabelece diferentes condiçóes de vida aos seus moradores.

A individualizaçáo e o poder de consumo caracterizam o estilo de vida das pessoas nas grandes cidades, conforme analisa Spósito (1994). Segundo esse autor, o lazer nas grandes cidades é diferenciado em função das condiçóes econômicas dos moradores. 
Nas pequenas cidades do interior, há uma relação maior de vizinhança e parentesco, o que possibilita laços de amizades mais amplos e difusos. De certa forma, os valores que outrora estiveram no mundo rural ainda são presentes nas pequenas cidades. Ocasionalmente, esses mesmos valores se manifestam nas periferias, nas "brechas metropolitanas", como enclaves "rurais" de fluxos de pessoas de uma mesma localidade e regiáo, deslocados para médias e grandes cidades.

No que diz respeito ao patrimônio imaterial, a cidade é guardiã de tradiçóes que, às vezes, se retraem ou se expandem e ganham visibilidade nas relaçóes cotidianas. Em Goiânia, há vários exemplos de tradiçóes rurais manifestas, o que significa que a dinâmica urbana não é forte suficientemente para inibir essas manifestaçóes culturais. As folias de reis, por exemplo, ganham visibilidade por meio de um encontro que ocorre há oito anos. Pela dinâmica mencionada, Cavalcanti (2001, p.30) aponta, nas contradiçóes da cidade de Goiânia, um modo de vida peculiar capaz de unir atividades da tradição pré-moderna às atividades do "circuito técnico de ponta".

\section{EXPERIÊNCIAS DE FESTAS RELIGIOSAS NA REGIÃO METROPOLITANA}

Num país de tradição religiosa católica, é comum a paróquia pioneira na cidade escolher seu padroeiro e este vir a ser também o santo padroeiro da cidade. No quadro abaixo, encontra-se urna relação das festas de padroeiros das cidades goianas que compóem a RMG.

Quadro 1 - Santos padroeiros dos municípios da

Região Metropolitana de Goiânia e suas festas

\begin{tabular}{|l|c|c|}
\hline \multicolumn{1}{|c|}{ Municípios } & Padroeiro( a) & Periodo da festa/2009 \\
\hline 01- Aparecida de Goiânia & N.S. Aparecida & $01 / 11$ de maio \\
\hline 02- Abadia de Goiás & N. S. Abadia & $14 / 15$ de agosto \\
\hline 03- Aragoiânia & Santa Luzia & 1 " semana de junho \\
\hline 04- Goiânia & N.S. Auxiliadora & 29 de maio \\
\hline 05- Goianira & São Geraldo & $17 / 18$ de outubro \\
\hline 06- Goianápolis & N. S. Aparecida & $11 / 12$ de outubro \\
\hline 07 - Hidrolândia & Santo Antônio & $12 / 13 / 14$ deiunho \\
\hline 08- Trindade & Divino Pai Eterno & $02 / 03 / 04 / 05$ de iulho \\
\hline 09- Nerópolis & Sáo Benedito & $01 / 02 / 03$ de agosto \\
\hline 10- Senador Canedo & N. S. Auxiliadora & $15 / 29$ de maio \\
\hline 11- Santo Antônio de Goiás & Santo Antônio & $13 / 14$ de junho \\
\hline 12- Bela Vista de Goiás & N. S. da Piedade & $25 / 26$ de iulho \\
\hline 13- Guapó & Sáo Sebastiáo & 11 de julho \\
\hline 14- Inhumas* & Santana & $25 / 26$ de Julho \\
\hline
\end{tabular}

Fontes: Site da Arquidiocese de Goiânia www.arquidiocesedegoiania.org.br. Acesso: abril/2009. Consulta telefônica nas paróquias locais. *Região Integrada de Goiânia.

De maneira geral, essas festas estão voltadas para a comunidade de cada localidade, o que envolve um grande número de devotos e também de não católicos. Algumas festas são realizadas fora da data consagrada ao padroeiro ou nos finais de semana próximos. Isso 
reflete Da frequência da festa, o que justifica certa flexibilização por parte da Igreja Católica em comemorar os seus santos nos dias atuais.

Vale ressaltar que a cidade de Trindade, na RMG, e sua festa religiosa é um diferenciador, pois já existe uma data consolidada. Nos nove primeiros dias de julho, a cidade recebe mais de um milhão de visitantes em sua tradicional Romaria do Divino Pai Eterno.

Outro destaque nessas festas é dado pela comemoração da padroeira de Goiânia, que tem seu dia celebrado com as programaçôes oficiais na Catedral da Arquidiocese, o que faz dessa um evento fora dos moldes tradicionais. As festividades contam, ainda, com a participaçáo expressiva de autoridades, políticos, na missa principal, fato que contribui para que a festa transforme-se em uma vitrine para que o político ganhe visibilidade e espaço para renovar os laços com o eleitorado.

Nos demais municípios, predominam festas com grande participação popular nas atividades religiosas e nas atividades de lazer. Envolvem quermesses, após as novenas, leilóes inclusive de animais - bingos e animados bailes festivos. Elas são um grande acontecimento local e uma fonte de renda para a paróquia.

\section{As Folias, Uma Tradição Sertaneja na Metrópole}

Para compreender as Folias, é necessário observar sua origem, no meio rural, e os ritos rurais nelas presentes. No Brasil, pesquisadores como Brandão (2007), Corrêa e Rosendahl (2008) entre outros se destacam na discussão desta temática e abrem novos horizontes a outros pesquisadores iniciantes nessa vertente. $\mathrm{Na}$ RMG, destacam-se, principalmente, Maia (2006), Pessoa (1993) e Coelho (2004) que desenvolvem investigaçóes sobre Festas e Folias de Reis.

$\mathrm{Na}$ presente investigação, fez-se um levantamento do calendário festivo de cada município e a sua categorização em Festas Cíclicas (FC) e Festas Profanas (FP). Recorreu-se a fontes específicas como igrejas, secretarias de turismo e demais órgáos em esferas municipais e estaduais para a formatação de um calendário.

A incidência de festas de perfil rural, mesmo com a expressiva urbanização da RMG, destaca-se em meio aos eventos cívicos. Como exemplo de festas com perfil rural, tem-se as Festas de Quadrilhas, de Peão e de produtos agrícolas para alimentos na época de colheitas. Ao analisar o Calendário de Festas é possível perceber um expressivo número de Folias de Reis em toda a Regiáo Metropolitana, as quais se iniciam na Capital, Goiânia, modificando ligeiramente o nome da festa: Festa de Santos Reis, Folia de Reis, Giros de Folias e, algumas vezes incluindo o nome do festeiro como Folia de Reis Luizinho, Folia de Reis Wilson Bispo, Folia de Reis da Dona Roxa ou o nome do lugar, caso da Folia na Morada do Morro.

A Folia de Reis tem sua origem no ato de relembrar os relatos bíblicos da jornada dos Reis Magos a Belém para presentear e adorar o Menino Jesus. A principal característica desta manifestaçáo está na dinâmica dos "giros", que consiste no percurso dos folióes para o rito de adoração ao Messias. Eles têm início nas vésperas do Natal e prosseguem até dia 6 de janeiro, dia de Reis. Durante os giros, os folióes visitam casas de devotos, rezam e cantam versos em adoração a Deus.

Segundo Jurkevics (2005), o formato dos Grupos de Folias trazido para o país durante o período colonial consiste em um cortejo, em que à frente sai o alferes da bandeira carre- 
gando o estandarte. Em seguida, os palhaços, com roupas coloridas e mascaras assustadoras, saltitam, dançam e animam o grupo.

Em Goiânia, o Encontro de Folias é comemorado há oito anos. Ele é realizado no mês de janeiro com eventual variação para o início do mês de fevereiro. A festa é promovida pela Prefeitura de Goiânia por meio da Secretaria Municipal de Cultura juntamente com Comissão Goiana de Folclore, unidos com o propósito de valorizar o patrimônio cultura1 imaterial e dar continuidade a essa tradição rural no estado.

Em 2009, participaram do Encontro de Folias 54 grupos, sendo 21 de Goiânia e 34 de outros municípios do estado (cf. Jornal Tribuna Campineira, 2009). A participação de folias de Goiânia no evento soma um total de 39 \% dos grupos que se apresentam; os municípios pertencentes à RMG somavam aproximadamente $19 \%$, e os demais $42 \%$. Vale ressaltar que nem todos os grupos pertencentes à RMG participam do Encontro.

Apesar de haver esse encontro anual, as Folias de Reis assim como as demais festas, consideradas como patrimônio imaterial, ainda padecem de açóes efetivas amparadas por políticas públicas, em todas as esferas governamentais.

\section{As Políticas para a Cultura e Para o Turismo na Região Metropolitana}

De acordo com a teologia cristã, o Menino Jesus foi presenteado pelos Reis Magos com Ouro, Incenso e Mirra que, respectivamente, significam Realeza, Divindade e Humanidade, pois este último constitui em um óleo utilizado no embalsamento de mortos.

Este representa os três Reis Magos diante da manjedoura em que o Menino fora encontrado.

Desde o ano de 2004, o PRT - Programa de Regionalização do Turismo Roteiros do Brasil" - tomou-se uma diretriz para estruturação e diversificação da oferta turística, do Plano Nacional de Turismo - PNT, lançado em 2007.

Atentos aos benefícios que podem ser gerados pelo turismo, os órgãos gestores da atividade no Estado de Goiás têm buscado desempenhar seus papéis em consonância com as diretrizes do PNT. A Agência Estadual de Turismo, Goiás Turismo, é o órgão oficial responsável pelo fomento do turismo. Na primeira etapa do Plano Estadual do Turismo, foi possível diagnosticar, de forma ampla, as características do turismo goiano e dimensioná-lo de maneira estratégica. Segundo Tavares (2008), ele traça a identidade turística de Goiás: cultura do interior. Além disso, recruta os tipos de turismo potenciais em Goiás: saúde, negócios e eventos, rural, ecoturismo e cultural em que se insere o turismo religioso.

Dentre as ações previstas para fomentar a economia do turismo no município de Goiânia, pela Secretaria Municipal de Turismo, no período 2009 a 2012, está o desenvolvimento de eventos temáticos que ressaltem a cultura goianiense.

Em relação às políticas públicas culturais, o Plano Nacional de Cultura é um instrumento de planejamento para médio e longo prazo, calcado nos esforços em garantir os direitos culturais aos brasileiros, respeitando a Constituição de 1988. Alguns estudiosos, dentre eles Botelho (2001), afirmam que, nos últimos anos, as políticas culturais no Brasil resumiram-se na criaçáo de leis de incentivo à culnrra. Eles afirmam que elas transferem a responsabilidade do governo para a sociedade, por meio da isençáo fiscal. Como exemplo, tem-se a Lei de Incentivo à Cultura Federal, popularmente denominada de Lei Rouanet. De acordo com os promotores de cultura e gestores de patrimônio cultural, os recursos destinados aos bens culturais não têm tido a devida atenção governamental. 
A Agência Goiana de Cultura Pedro Ludovico Teixeira - Agepel - é o órgão responsável pela gerência da cultura em Goiás. Suas açóes se materializam em frentes que envolvem desde o patrocínio aos eventos, divulgação e melhoria da infra-estrutura local, até a elaboração de projetos de mecenato e alocação de recursos juntos ao Ministério da Cultura.

A cultura goiana é muito rica em manifestaçóes espontâneas de entretenimento e de religiosidade, com costumes que perpassam geraçóes há mais de dois séculos. São necessários cuidados para que muitas manifestaçóes não se percam no tempo, seja pela falta de recursos e de políticas, seja pela não valorização por parte das novas geraçóes.

\section{CONSIDERAÇÓES FiNAIS}

O turismo ainda não constitui um instrumento de valorizaçáo do patrimônio imaterial em Goiás e apenas recentemente começou-se a implementar uma política de valorização do patrimônio, sobretudo, do arquitetônico da RMG.

A Secult optou como prioridade para suas açóes de políticas públicas a inauguração das Casas de Cultura em bairros da periferia de Goiânia, a requalificação de espaços culturais como a Estaçáo Cultura, o Museu de Arte de Goiânia, reinaugurado em 2003, o Palácio da Cultura e a Biblioteca Marieta Telles Machado (atual Complexo Cultural Chafariz - Praça Universitária); a reconstrução do Coreto da Praça Joaquim Lúcio, no Setor Campinas; restauraçáo do Grande Hotel, no Centro da cidade; criação do Centro Tecnológico do Espetáculo e a refonlla do Centro Livre de Artes - CLA (SECULT, 2009). Essas são obras que ressaltam a valorizaçáo de patrimônio dito de "pedra e cal" e de equipamentos que materializam as açóes políticas.

Ainda há, no entanto, uma lacuna a ser preenchida no que diz respeito aos incentivos que são dados aos grupos folclóricos, ao artesanato, às danças, enfim, às manifestaçóes de cunho religioso com relaçóes com o rural - como as festas juninas e folias de reis.

As festas de caráter religioso e rural são marginalizadas da vida pública e das políticas culturais do município de Goiânia, repetimos. Nos calendários festivos dos municípios interioranos, apenas as tidas como tradicionais persistem por meio da memória de poucos e necessitam ser valorizadas por constituírem a memória de um povo, de uma história e de um tempo da sociedade contemporânea.

É evidente a preocupação econômica com o desenvolvimento do turismo.

Contudo. o plano analisado e as políticas estaduais e municipais em andamento não revelam qualquer valorizaçáo de festas e de folias mais tradicionais. Isso pode supor que tais manifestaçóes culturais, no entendimento dos agentes do turismo, não se constituem promotores econômicos.

Convém ressaltar que a mescla entre cultura e turismo, que ocupa um inciso do art $3^{\circ}$, da Lei Geral do Turismo, chama a atenção para o risco de comprometer a rica identidade cultural das comunidades locais. Conforme foi dito, o desinteresse por parte dos idealizadores do turismo revela-se na exclusão do patrimônio imaterial, no caso de Goiânia e pode ter uma dupla e contraditória interpretação: uma ameaça e/ou uma proteção à identidade cultural. A criação de políticas públicas destinadas à cultura e ao turismo, quando bem concebidas, é, sem dúvida, instrumento valioso para o patrimônio de um dado povo. 


\section{REFERÊNCIAS BIBLIOGRÁFICAS}

Botelho, Isaura. 2001, Dimensões da cultura e políticas pública. [online]. Available at: <http://www.scielo.br/ /scielo.phpscript=sci_arttext\&pid=SOI02-88392001000200011\&lng=e m \& nnn=iso > Accessed Oct 15, 2009.

Brandão, C. R. 2007, Os Deuses do Povo: um estudo sobre a religiáo popular, 3rd edn, EDUFU, Uberlândia.

Carvalho, P. F. de. 2001, Lazer e Turismo em espaços urbanos: o caso da Avenida Paulista-SP. In: FARIA I. F. de. (ed) Turismo: lazer e políticas de desenvolvimento local. Editora da Universidade do Amazonas, Manaus.

Cavalcanti, L.S. (ed). 2001, Geografia da Cidade: a produção do espaço urbano de Goiânia. Editora Alternativa, Goiânia.

Coelho, T. O. 2004, O comércio varejista periódico na Festa do Divino Pai Eterno em Trindade, Go. Dissertação de Mestrado em Geografia. Instituto de Estudos Sócio-Ambientais da UFG, Goiânia.

Corrêa, R. L. \& Rosendahl, Z. (ed). 2008, Espaço e Cultura: pluralidade temática. EdUERJ, Rio de Janeiro.

Jornal Tribuna Campineira, Available at: <http:lhvwv.'.tribunacampineira.com. r/index.php?view=article\&id= 755:-8d-encontro-de-folia-de-reis-sera-realizado-no-domingo\&option=com_content\&Itemid=12> Accessed Oct 15,2009 .

Jurkevics, V. I. 2005, Festas religiosas: a materialidade da fé. Revista de História: Questôes \& Debates. Editora UFPR, Curitiba, no.43, pp.73-86.

Ministério do Turismo, Lei Geral do Turismo. Available at: http://www.turismo.gov.br/turismo//legislacao/ /legislacao_geral/11771 Jei.htrn1 Accessed Oct 15, 2009.

Maia, C. E. S. \& Coelho, T. O. 2006, Tradiçōes na festa do Divino Pai Eterno em Trindade (GO): Comércio periódico e romaria de carros de bois. Agrária, São Paulo, vol. 3, pp. 103-122.

PNC, Plano Nacional de Cultura: Diretrizes Gerais (2008). la ed. p. 12. Available at: <http//www.cultura.gov.br/ pnc> Accessed Oct 15, 2009.

Pessoa, I. M. As falas de reis. ln: Jadir de Morais Pessoa. (ed). 1993, Meu senhor dono da casa: Os 50 anos da Folia de Reis das Lages. 1st edn, Gráfica O Popular, Goiânia.

PRT. Programa de Regionalização do Turismo. Ministério do Turismo. Available at: <http://200.143 .12. 83/portalmtur/opencms/regionalizacao/modulos/ operacionais/arq uivos/sustentabilidade.htrn1> Accessed Nov 25, 2009.

RMG, Regiẫo Metropolitana de Goiânia. Prefeitura de Goiânia. Available at: <http://www.goiania.go.gov.brlhtrn1/ /principallgoianialregiaometropolitanalregiaometropolitana.shtrn1> Accessed Nov 15,2009.

Santos, M. \& Silveira, M.L. 2001, O Brasil: território e sociedade no inicio do século XXI. Editora Record, Rio de Janeiro.

Seclj1 1. 2009. Secretaria Municipal de Cultura. Prefeitura de Goiânia. Available at: <http:// www.goiania.go.gov. .brlhtrn1/culturalindex.htm> Accessed Jun 13, 2009.

Spósito, E. S. 1994, A Vida nas Cidades. Contexto, São Paulo.

Tavares, L. 2008. Turismo tem um 'plano' para o crescimento. Available at: <http://vww.sebraego.com.br/site/ /site.do?idArtigo=3312> Accessed May 23, 2009.

Vallbona, M. C \& Costa, M. P. 2003, Patrimonio Cultural. Editora Sintesis, Madrid. 